\title{
FRACTURE RESISTANCE OF MAXILLARY PREMOLARS RESTORED WITH DIFFERENT FIBER-REINFORCED COMPOSITES: AN IN VITRO STUDY
}

\author{
Hebatallah M. Taher * and Mohamed Haridy **
}

\begin{abstract}
Objective: To evaluate the fracture resistance of maxillary premolars weakened by MOD cavities and restored with nanohybrid composite, bulk fill composite and two fiber reinforced composites.

Materials and Methods: A total of 60 sound maxillary first premolars with standardized MOD cavities were used for this study, except for intact control. Specimens were randomly divided into six groups ( $n=10)$; G1: sound premolars (negative control); G2: unrestored teeth (positive control); G3: MOD cavities restored with nanohybrid composite. G4: MOD cavities restored with sonicfill bulk fill composite.; G5: MOD cavities restored with nanohybrid resin composite with glass fibers embedded into it from bucco-lingually.; G6: MOD cavities restored with short-fiber reinforced resin composite. All specimens were subjected to thermocycling between $5 \mathrm{C}^{\circ}$ to $55 \mathrm{C}^{\circ}$ in water bath for a total of 2000 cycle with 10 seconds dwell time. Then specimens were individually mounted on a computer-controlled material testing machine (Instron 3345) with a load cell of $5 \mathrm{kN}$ and the maximum load to produce fracture in Newton $(\mathrm{N})$ was recorded and statistical analysis was performed.
\end{abstract}

Results: Kruskall-Wallis test and Bonferroni-corrected Mann-Whitney U test showed that there was a statistically significant difference between the different study groups $(\mathrm{P}=0.000)$. Positive control and short fiber reinforced composite groups yielded the significantly highest mean values; followed by nanohybrid resin composite, sonic fill bulk fill composite and fiber reinforced composite groups that were statistically similar. While the negative control had the significantly lowest mean value.

Conclusion: The use of short fiber reinforced resin composite as restoration significantly increased the fracture strength of premolars with MOD restorations.

KEYWORDS: MOD cavities, Nanohybrid composite; Bulk fill composite; fiber reinforced composite; Fracture strength.

* Associate Professor of Conservative Dentistry, Faculty of Dentistry, Cairo University and October University for Modern Science and Art .

** Associate Professor of Conservative Dentistry, Faculty of Dentistry, Cairo University and British University in Egypt. 


\section{INTRODUCTION}

It is well known that the main function of a tooth is mastication. The tooth acts as a mechanical device for grinding food. An intact natural tooth performs flexion or bending during the mastication process. However, tooth fracture remains a major complication of premolars especially if weakened with cavity preparations. Nowadays, composite restorations are the most commonly used fillings according to the increase in patients' demands for esthetics and the preservation of tooth structure. Fracture resistance is one of the most important properties of dental materials depending on the material resistance to crack propagation internally and/or externally. These cracks can cause marginal or bulk fractures of the restoration [1]. Recent researches have focused on several concerns related to weakening of the teeth after MOD preparations and the effect of restorative material and technique in strengthening the remnant tooth structure ${ }^{[2,3]}$. Many factors were considered to be accountable for the compromised fracture resistance of the restored teeth. Among these factors the cavity preparation itself that causes significant reduction in tooth strength, especially with MOD cavities, due to the loss of marginal ridges and fatigue of the brittle tooth structure as result of propagation of microcracks under repeated occlusal forces [4, 5]. Moreover, fracture of the cusps in teeth with wide cavities occurs as result of the occlusal loads that deflect cusps from each other ${ }^{[6,7]}$. Therefore, strengthening of such teeth is of importance to improve their fracture resistance. Advancements in the bonded restorations have significantly improved the fracture resistance of teeth by uniting the restorations to the teeth ${ }^{(8)}$ with better load analysis. Moreover, the new dental composites have been manufactured to improve their mechanical properties. However, the relatively high brittleness and low fracture toughness of current resin composites still their major shortcoming in stress-bearing posterior restorations. Many clinical strategies have been suggested to improve fracture resistance of MOD restorations including incremental packing of composite, using bulk-fill composite and using recently introduced fiber reinforced resin composites. Reinforcing composite with short fibers has been used to control the crack propagation from its internal defects. It uses a polymethylmethacrylate(PMMA)dimethacrylate based semi interpenetrating polymer network (semi- IPN) polymer matrix with randomly distributed $\mathrm{E}$ glass fibers ${ }^{(9)}$. The introduction of short fiber- reinforced composite (SFC) resin, has gained attention recently as a restorative material and is advised to be used in high stress-bearing areas ${ }^{(10,11)}$. Its randomly oriented short glass fiber fillers composed of a combination of barium glass and silanated E-glass fibers is claimed to provide an isotropic reinforcement in multiple directions instead of single or double directions ${ }^{(12)}$.

Therefore, the aim of this study was to evaluate the fracture resistance of maxillary premolars weakened by MOD cavities and restored with nanohybrid composite, bulk fill composite and two different fiber reinforced composites. The null hypothesis of this study was that the different resin composite materials would not affect the fracture strength of the restored MOD cavities in maxillary premolars.

\section{METHODOLOGY}

\section{Sample selection:}

A total of sixty recently extracted intact, crack and caries-free human maxillary first premolars, extracted for periodontal reasons, were selected for this study. The teeth were examined for being approximately homogeneous in anatomic crown length, mesiodistal and buccolingual dimensions. For the purpose of standardization, the teeth were selected with approximate similarity in crown size, length and shape. They were of average dimensions $(7 \pm 0.5 \mathrm{~mm})$ mesio-distal width, and of bucco-lingual width $(8 \mathrm{~mm} \pm 0.5 \mathrm{~mm})$. All 
dimensional measurements were taken at the proximal cementoenamel junction (C.E.J) level using a digital caliper. Any premolars with other dimensions than formally stated were excluded. These measurements were used in the distribution of the teeth among the different groups to provide uniformity of tooth size in each group. All gingival remnants were removed; the crowns were cleaned and scaled with hand instrument and polished with a rotating brush and pumice. Then the collected teeth were stored in saline solution at room temperature from the day of extraction until the time of testing, to keep them hydrated and prevent cracking during preparation.

\section{Sample grouping}

The teeth were randomly divided into six groups (10 each) according to the restorative materials applied. The materials for the restorative procedures are listed in Table 1.

Group 1: sound premolars without cavity preparation as negative control.

Group 2: premolars with cavity preparation but without restoration as positive control.

Group 3: the prepared cavity was restored with nanohybrid resin composite.

Group 4: the prepared cavity was restored with sonicfill bulk fill composite.

Group 5: the prepared cavity was restored with nanohybrid resin composite with glass fibers embedded into it bucco-lingually.

Group 6: the prepared cavity was restored with short-fiber reinforced resin composite.

TABLE (1) Name and product details of the materials used

\begin{tabular}{|c|c|c|c|}
\hline Material & Specifications & Composition & Manufacturer \\
\hline $\begin{array}{l}\text { Ceram x- } \\
\text { SpherTEC }\end{array}$ & $\begin{array}{c}\text { Nanohybrid } \\
\text { composite } \\
\text { material }\end{array}$ & $\begin{array}{l}\text { Matrix: (methacrylate-, acid-modified methacrylate-, inorganic } \\
\text { polycondensate- or epoxide based) modified version of the polysiloxane. it } \\
\text { is combined with a well-established poly-urethane-methacrylate as well as } \\
\text { bis-EMA and TEGDMA. } \\
\text { Fillers: } 77-79 \text { weight- } \% \text { total ( } 59-61 \% \text { by volume) }\end{array}$ & $\begin{array}{l}\text { DENTSPLY } \\
\text { sirona, , } \\
\text { Konstanz, } \\
\text { Germany }\end{array}$ \\
\hline SonicFill ${ }^{\mathrm{TM}}$ & $\begin{array}{l}\text { Nanohybrid } \\
\text { bulkfill } \\
\text { composite } \\
\text { material }\end{array}$ & $\begin{array}{l}\text { Matrix: Glass, oxide, chemicals }(10-30 \%) \text {, 3-trimethoxysilylpropyl methac- } \\
\text { rylate }(10-30 \%) \text {, silicon dioxide }(5-10 \%) \text {, ethoxylatedbisphenol A dimeth- } \\
\text { acrylate }(1-5 \%) \text {, bisphenol } \\
\text { A bis(2-hydroxy-3- methacryloxypropyl) ether (1-5\%), and TEGDMA (1- } \\
5 \%) \\
\text { Filler: } 83.5 \% \text { by weight }\end{array}$ & $\begin{array}{l}\text { Kerr }^{\mathrm{TM}} \\
\text { Corporation, } \\
\text { West } \\
\text { Collins, } \\
\text { Orange, CA }\end{array}$ \\
\hline $\begin{array}{r}\text { Interlig } \\
\text { Fiber }\end{array}$ & $\begin{array}{l}\text { Glass fibers } \\
\text { preimpregnated } \\
\text { in light curable } \\
\text { composite resin }\end{array}$ & $\begin{array}{r}\% 5 \mathrm{wt} \pm 60 \text { :Glass fibers } \\
: \text { Impregnated resin } \\
.5 \mathrm{wt} \%: \text { Bis-GMA, diurethane, barium glass, silicon dioxide, catalysts } \pm 40 \\
(\% 7.3 \mathrm{wt}) \text { TEGDMA ,(\%27.8) Resin matrix: Bis-GMA, UDMA } \\
\text { Fillers: (a) barium glass, ytterbium trifluoride, mixed oxide, silicon dioxide } \\
(\% \mathrm{wt} 1.1) \mathrm{wt} \%) \text { (b) Additives, stabilizers, catalysts, pigments } 63.8)\end{array}$ & $\begin{array}{l}\text { Angelus, } \\
\text { Londrina, } \\
\text { PR, Brazil }\end{array}$ \\
\hline $\begin{array}{r}\text { EverX } \\
\text { Posterior }\end{array}$ & $\begin{array}{r}\text { short-fiber } \\
\text { reinforced resin } \\
\text { composite }\end{array}$ & $\begin{array}{r}\text { Resin matrix: Semi-interpenetrating polymer network (semi-IPN): net- } \\
\text { poly(methyl meth'acrylate)-inter-net-poly(bis-glycidyl- A-dimethacrylate): } \\
\text { Bis-GMA, TEGDMA, and PMMA } \\
\text { Fillers: E-glass fiber, barium borosilicate }\end{array}$ & $\begin{array}{l}\text { GC) } \\
\text { Company, } \\
\text { Tokyo, } \\
\text { (Japan }\end{array}$ \\
\hline
\end{tabular}




\section{Samples preparation}

\section{Fabrication of mold and centralizing device:}

Specially designed cylindrical Teflon mold formers having $2 \mathrm{~cm}$ length and $2 \mathrm{~cm}$ internal diameters were fabricated. Its cylindrical tube used for holding of the epoxy resin and the tooth inside it. Accurate centralization of the teeth in the epoxy resin was done using a specially designed centralizing metal device for standard placement.

\section{Periodontal ligament simulation and Mounting of the teeth}

For periodontium simulation, the roots of all teeth were dipped in melted set up wax (Cavex, Holland B.V) to a depth of $2 \mathrm{~mm}$ away from cemento-enamel junction to form a uniform coat of about $0.3 \mathrm{~mm}$ around root. After wax setting, each tooth is casted in self-cure acrylic resin cylindrical block (Acrostone, Egypt). Each tooth was embedded in the acrylic while it was in soft dough stage and the tooth was pressed in the acrylic till all root is embedded except for $2 \mathrm{~mm}$ apical to cemento-enamel junction with the long axis of the tooth perpendicular to the base of the block. The cylinder Teflon mold was seated into the stainlesssteel base of centralizing advice, and then applying separating medium on walls of the mold .The crown of each tooth was clamped by the crown holder. The tooth was centralized guided by the centralizing depression in the stainless-steel base. When the axis of the tooth was positioned correctly, acrylic was poured inside the mold until it completely filled it. The acrylic was left to harden then pushed with the tooth outside the mold. After acrylic setting the block was removed from the mold and checked carefully. Then the teeth were removed from the casted acrylic block, wax spacer was removed and light body poly-vinyle siloxane material (Speedex, Coltene Whaldent AG, Attstatten, Switzerland) was injected in the space between mold and root then teeth were re-inserted in the mold. This simulated the periodontal ligaments. The specimens were stored in distilled water in $37{ }^{\circ} \mathrm{C}$ temperature for 24 hours before testing.

\section{Standardized Tooth Preparation:}

All teeth were planned to receive standardized MOD cavity preparation except Group 1 "sound teeth"; teeth in this group were kept without cavity preparation to act as negative control. As for teeth in groups 2 to 6 , a line was drawn at cementoenamel junction on the two proximal surfaces of each tooth by a waterproof marker (Faber Castell, Germany), then 2 lines were drawn from cusp tips to cementoenamel junction to represent inter-cuspal distance. Cavity dimensions were then measured using a digital caliper and the cavity outline was drawn centered in the inter-cuspal distance formally measured. The dimensions of the cavity were as follow; occluso-cervical depth $=4 \pm 0.2 \mathrm{~mm}$ and buccolingual width $=3 \pm 0.2 \mathrm{~mm}$. A fissure carbide bur with rounded end was used to prepare the cavities (Healthico, USA) in a high-speed handpiece (PANA MAX, NSK, Japan) under copious amount of water. The carbide bur was changed every 5 preparations. After preparation, cavity dimensions were rechecked by the digital caliper.

\section{Restoration of the prepared cavities:}

A matrix retainer system, a holder and a metal matrix, (Tofflemire, Miltex Inc, York, PA, USA) was used to simulate the clinical conditions. All prepared teeth received restorations except group 2 "Cavity preparation without restorations" to act as the positive control. The application of all tested materials was performed in accordance with the manufacturer's instructions using their recommended adhesives of the same company. For all specimens the etch-and-rinse adhesive approach was applied according to the manufacturer's instructions. All cavities were etched for 30 seconds using $37 \%$ phosphoric acid, rinsed with water for 10 seconds and dried with air for 5 seconds. Then, the 
adhesive was applied for all specimens according to the restoration material used and polymerized using LED light-curing unit (Elipar S10, 3M ESPE, St Paul, MN, USA) operating in standard mode at light intensity $1200 \mathrm{~mW} / \mathrm{cm}^{2}$. Light intensity output was checked every 10 restorations with a radiometer from the same manufacturer. The prepared cavity was restored as follows;

Group 3: after application and curing of the adhesive (Prime and Bond Universal, DENTSPLYSirona, Konstanz, Germany) the cavity was restored incrementally with Ceram- $\mathrm{X}$ SpherTEC. The first increment was $2 \mathrm{~mm}$ thickness and applied horizontally to ensure maximum adaptation with the floor and cured for 20 seconds using the same light curing unit. Afterwards the second increment was applied and cured for another 20 seconds.

Group 4: after application and curing of the adhesive (OptiBond Universal, Kerr ${ }^{\mathrm{TM}}$ Corporation, West Collins, Orange, CA) the cavity was restored with Sonicfill bulk fill composite. Mounting of the Sonicfill handpiece to the high-speed aerator was done, followed by placing the composite compule into the tip of the device. Then, the speed of composite ejection from the sonicfill handpiece was adjusted to speed 3. Upon activation of the handpiece, resin composite flowed into the cavity in one increment. The tip of the compule was always at a lower level than the ejected composite material inside. After turning off the hand piece, composite was packed using ball burnisher and the excess material was removed before curing. Then, curing for 20 seconds was done according to the manufacturer's instructions with the same light curing unit.

Group 5: after application and curing of the adhesive (Prime and Bond Universal, DENTSPLY Sirona, Konstanz, Germany) the cavity was restored incrementally with Ceram-x-SpherTEC. The first increment was $2 \mathrm{~mm}$ thickness and applied horizontally to ensure maximum adaptation with the floor, the Interlig Fibers were embedded into the uncured resin composite from the buccal surface toward the lingual surface and then cured for 20 seconds using the same light curing unit. Afterwards the second increment was applied and cured for another $20 \mathrm{sec}$ onds.

Group 6: after application and curing of the adhesive (G-Premio Bond,GC Company, Tokyo, Japan) the cavity was restored incrementally with fiber reinforced resin composite Ever X posterior. The first increment was $2 \mathrm{~mm}$ thickness and applied horizontally to ensure maximum adaptation with the floor and cured for 20 seconds using the same light curing unit. Afterwards the second increment was applied and cured for another 20 seconds.

Finally, all restorations were finished and polished using Sof-Lex ${ }^{\mathrm{TM}}$ discs (3M ESPE, USA) with aluminum oxide coating of four descending grits.

\section{Thermocycling:}

All specimens were subjected to thermocycling between $5 \mathrm{C}^{\circ}$ to $55 \mathrm{C}^{\circ}$ in water bath for a total of 2000 cycle with 10 seconds dwell time at each bath using thermocycling device.

\section{Fracture resistance testing}

The specimens were blinded from the assessing personnel by placing them in sequentially numbered sealed light proof containers. The specimens were individually mounted on a computer-controlled materials testing machine (Model 3345; Instron Industrial Products, Norwood, MA, USA) with a load cell of $5 \mathrm{kN}$ and data were recorded using computer software (Instron ${ }^{\circledR}$ Bluehill Lite Software). The specimens were mounted and secured on the lower fixed compartment of the testing machine by tightening screws, to ensure that the loading steel rod with spherical tip of 6-mm diameter was positioned on the central occlusal surface of the restoration in such way the load applicator tip only touched the inclined planes of buccal and lingual cusps. The 
loading steel rod with spherical tip was attached to the upper movable compartment of the machine traveling at cross-head speed of $1 \mathrm{~mm} / \mathrm{min}$. A layer of tin foil (1mm thickness) was placed between the loading tip and the occlusal surface of the overlay to achieve an even stress distribution and to minimize the transmission of local force peaks. The tip contacted the occlusal surface of the overlay restoration which was subjected to a slowly increasing vertical load $(1 \mathrm{~mm} / \mathrm{min})$ until the fracture occurred. The load at failure in Newtons was manifested by an audible crack and confirmed by a sharp drop of loaddeflection curve. The maximum load to produce fracture for each specimen in Newton (N) was recorded and the fracture modes were evaluated..

\section{Statistical analysis:}

Statistical analysis was performed using IBM SPSS Statistics Version 2.0 for Windows. Data was presented as mean and standard deviation (SD). The significance level was set at $\mathrm{P} \leq 0.05$. KolmogorovSmirnov and Shapiro-Wilk tests were used to assess data normality. Multiple comparisons between study groups were performed using Kruskall-Wallis test and Bonferroni-corrected Mann-Whitney U test.

\section{RESULTS}

Kruskall-Wallis test and Bonferroni-corrected Mann-Whitney $U$ test showed that there was a statistically significant difference between the different study groups $(\mathrm{P}=0.000)$. Positive control and short fiber reinforced composite groups yielded the significantly highest mean values; followed by nanohybrid resin composite, sonic fill bulk fill composite and fiber reinforced composite groups that were statistically similar. While the negative control had the significantly lowest mean value.

TABLE (1) Mean \pm SD and P-value for the effect of restoration type on fracture resistance of MOD cavities in maxillary premolars (Newtons).

\begin{tabular}{|c|c|}
\hline Groups & Mean \pm SD \\
\hline Sound Teeth (Positive Control) & $992.84 \pm 117.16^{\mathrm{a}}$ \\
\hline MOD Cavity (Negative Control) & $459.52 \pm 90.66^{\mathrm{c}}$ \\
\hline Nanohybrid Resin Composite & $827.07 \pm 60.90^{\mathrm{b}}$ \\
\hline Sonic Fill Bulk fill Composite (SF) & $825.99 \pm 60.68^{\mathrm{b}}$ \\
\hline Fiber Reinforced Composite & $846.45 \pm 66.16^{\mathrm{b}}$ \\
\hline Short Fiber Reinforced Composite & $1010 \pm 109.72^{\mathrm{a}}$ \\
\hline P-value & 0.000 \\
\hline
\end{tabular}

Significance level: $P \leq 0.003$

Means with identical superscript letters are statistically significantly different at $P \leq 0.003$.

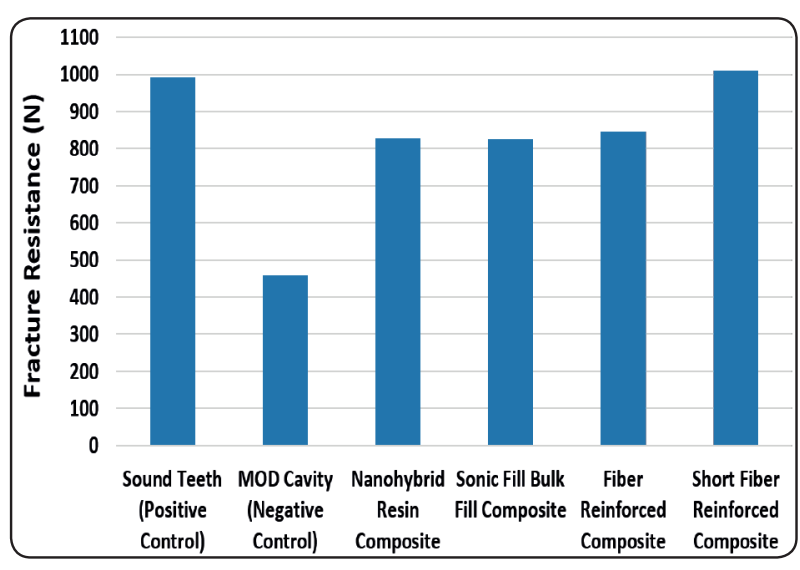

TABLE (2) levels of fracture in different study groups

\begin{tabular}{|c|c|c|c|c|c|c|}
\hline Level of fracture & $\begin{array}{c}\text { Group 1 } \\
(\mathrm{n}=10)\end{array}$ & $\begin{array}{c}\text { Group 2 } \\
(\mathrm{n}=10)\end{array}$ & $\begin{array}{c}\text { Group 3 } \\
(\mathrm{n}=10)\end{array}$ & $\begin{array}{c}\text { Group 4 } \\
(\mathrm{n}=10)\end{array}$ & $\begin{array}{c}\text { Group 5 } \\
(\mathrm{n}=10)\end{array}$ & $\begin{array}{c}\text { Group 6 } \\
(\mathrm{n}=10)\end{array}$ \\
\hline Enamel & 10 & - & 6 & 7 & 3 & 9 \\
\hline Dentin & - & - & 4 & 3 & - & 1 \\
\hline At or below CEJ & - & 10 & - & - & - \\
\hline
\end{tabular}




\section{DISCUSSION}

Resin based composite (RBC) restorations are considered the major daily work in restorative dentistry. Several negative effects in resin based composite materials are related to their mechanical properties and polymerization shrinkage [13]. Despite innovations in resin composite, indirect esthetic restorations still the first choice for extensive cavities in high stress-bearing areas. This is due to limitations of resin composite as their high brittleness, low fracture toughness and formation of microcracks in the weakened tooth structure induced by polymerization shrinkage ${ }^{(14)}$. Therefore, A new technologies were introduced with resin- based composite material as the bulk-fill composite that could be cured in 4 to $5 \mathrm{~mm}$ thick increment in one step. This is achieved by better light transmission and novel photo-initiators. Moreover, they are designed to reduce cuspal flexure by reducing the polymerization shrinkage ${ }^{(15)}$. Another innovation is strengthening of composite with microglass fibers, a fiber-reinforced substructure, whiskers, and particulateceramic fillers toimprove theirmechanical properties ${ }^{(16-17)}$. The fiber reinforced bulk fill resin composite that is consisting of short E-glass fibers dispersed randomly in multi-directions in a semi interpenetrating network resin matrix comprised of both linear and cross-linked polymer phases as PMMA, bis-GMA, TEGDMA and HEMA. It was found that short E-glass fiber reinforced composite (SFRC) is a good candidate to be used as a base or dentin substitute for reinforcement of weakened tooth structure. Whereas the unidirectional fibers have a continuous direction in one dimension used as a ribbon inserted in the cavity preparation before or during insertion of composite. Unidirectional fibers give superior strength compared to short fibers, but only when the direction of stress is the same as that of the direction of the fibers ${ }^{(18)}$. E-Glass fiber ("E" stands for electric) is made of alumino- borosilicate glass with less than $1 \mathrm{wt} . \%$ alkali oxides. Some other elements may also be present at low impurity levels. A typical nominal chemical composition of E-glass fibers is $\mathrm{SiO} 254$ wt.\%, $\mathrm{Al} 2 \mathrm{O} 314$ wt. $\% \mathrm{CaO}+\mathrm{MgO}$ 22 wt. $\%, \mathrm{~B} 2 \mathrm{O} 310 \mathrm{wt} . \%$ and $\mathrm{Na} 2 \mathrm{O}+\mathrm{K} 2 \mathrm{O}$ less than 2 wt. ${ }^{(19)}$. The enhancement of the properties of fiber reinforced composite in general is due to the stress transfer from the matrix to the fibers, depending on the fiber's length, diameter and also due to the action of the fibers in stopping crack propagation through the material. Additionally, the technique sensitivity remains a main concern for dentists for achieving successful results. Maxillary premolar teeth were used in this study because during mastication the anatomic shape of premolars creates a tendency for the separation of cusps. Siso et al ${ }^{(20)}$ reported that MOD preparation without restoration reduced tooth strength up to $(50 \%)$ due to loss of marginal ridges compared with sound premolar teeth. Moreover, in this study, the MOD cavity was prepared in proportion to the tooth dimension in order to simulate the worst clinical situation. So, this study investigated fracture resistance of maxillary premolars weakened by MOD cavities and restored with nanohybrid composite, bulk fill composite and fiber reinforced composite.

In the current study, MOD cavity design was prepared in premolar teeth to weaken the remaining tooth structure and favor cuspal fracture. The bucco-palatal width was standardized in all teeth to be within differences of a maximum 5\% between the teeth to ensure comparisons in each group and between groups. It would be expected that, irrespective of layering protocol used, all of the restored teeth should present higher fracture resistance values when compared to the prepared unrestored teeth because the modulus of elasticity of resin composite would restore the fracture resistance as well as guide the fracture mode ${ }^{[21,22]}$. These findings are consistence with the present study that observed lowest fracture resistance values in unrestored group. The results of this study confirmed that various resin composite materials used had essential role for improving the fracture resistance and the fracture resistance of the groups 
restored with different composite materials showed nearest value to the unprepared teeth and was significantly higher than that without restoration, which supports the findings of previous studies ${ }^{[23,}$ 24].

The nanohybrid $R B C$ and bulk fill $R B C$ acted similarly in terms of fracture resistance. This may be due to the rheological similarity that is based upon methacrylate matrix consisting of BisGMA,TEGDMA and the inorganic silica fillers. The difference is in the photo-initiator system that is modified in bulk fill RBC to enable it to be cured in $4 \mathrm{~mm}$ thickness. The photo-initiator apparently succeeded in its claimed role with efficient degree of conversion (25). This is emphasized by the approximate results found when comparing it with incrementally packed nanohybrid RBC. Undercured RBC leads to a drop in mechanical and physical properties of composites which did not happen with the bulk fill RBC ${ }^{(26)}$. In addition, the strategy of decreasing polymerization shrinkage and polymerization shrinkage stresses employed in bulk fill RBC may have attributed in increasing fracture resistance. Polymerization shrinkage causes tension on cavity walls that induces microcracks that predispose future fractures. Elimination of shrinkage and shrinkage stresses by bulk fill RBC decreases the probability of occurrence of this mechanism ${ }^{(27)}$. The results found are consistent with a study by Vahid et al comparing the fracture resistance of MOD cavities in maxillary premolars restored with bulk fill RBC or Nano composite ${ }^{(28)}$. Also, another study by Fahad and Majeed ${ }^{(29)}$, by Baban and Atiyah ${ }^{(30)}$ and by Toz et al. ${ }^{(31)}$ were in agreement with the found results. They all found that bulk fill composites act similar to nanohybrid $\mathrm{RBC}$ in terms of load bearing capacity when used in MOD cavities and can be used reliably as nanohybrid RBCs. In contrast, a study by Didem et al found that compressive strength of bulk fill either flowable or packable is significantly lower than conventional composites ${ }^{(32)}$. The bulk fill
RBC used in the fore mentioned study are SDR and Tetric evoceram with filler loading $79 \%-81 \%$, and $68 \%$, respectively which is less than filler loading in sonicfill which constitutes up to $83 \%$. Filler loading is a crucial factor in load bearing capacity. Also, the mechanical testing was performed by the use of cylindrical samples of each material according to American Dental Association (ADA) specifications ( $3 \mathrm{~mm}$ diameter $\times 6 \mathrm{~mm}$ height) unlike methodology used in this study by testing restoration in MOD cavities. This might alter the stress reaction of the tested objects.

\section{Regarding the effect of using fiber reinforced} composite, composite reinforced with polyethylene fibers and glass fibers (IFC) (Interlig Fibers) have been shown to have a better effect on the fracture resistance treated teeth ${ }^{(33,34)}$. This improvement depends on many factors including the resin composite used with them; the quantity of the fibers used, length, form, orientation of the fibers; and the adhesive system used (35-36). The main problem in using theses fibers is their application method. These fibers were embedded in the uncured composite which might create a discontinuous phase with the continuous polymer resin matrix leading to discontinuous interface that will act as stress raisers inducing stress concentration ${ }^{(37)}$. This study used the recently introduced short fiber reinforced composite (SFC) (everX Posterior), which is commonly used as a substructure covered with a layer of composite ${ }^{(35,38,39)}$, as a restorative material that fill the whole cavity. The IFC showed less fracture resistance compared with SFC resin composite, which was statistically significant. The reasons might be attributed to application technique as they are embedded in the composite before curing with the possibility of formation of voids during this placement forming huge oxygen-inhibited areas inside the restorations ${ }^{(40)}$. Furthermore, glass fibers are more rigid and not easily adapted to the walls and floor of the cavity resulting in uneven thickness of the composite causing decreased functionality of 
the reinforced composite in clinical conditions ${ }^{(41)}$. Moreover, theses glass fibers are of lower flexural resistance (282 MPa [Norma ISO 10477]) that affect their strengthening performance. Oskee et al ${ }^{(42)}$ showed that there was increased fracture resistance when glass fibers were placed on the occlusal third instead of the gingival third of the cavities. The proximity of the fiber location to the force exertion point and maintaining the buccal and lingual cusps close to each other by occlusal surface fibers protect the natural cusps, resulting in higher fracture resistance. In this study, the fibers were placed near the floor of the cavity rather than on the occlusal third for standardization, and this could have influenced the results of the study. The SFC resin showed a significant increase in fracture resistance $(1010 \pm$ 109.72). This might be attributed to that the SFC fibers are pre-incorporated in the resin transferring the subjected stresses from the polymer matrix to the fibers acting as crack stoppers. According to the Krenchel factor, short randomly arranged fibers (E-glass fibers) when incorporated in the resin matrix provide an isotropic reinforcement effect in multiple directions instead of just 1 or 2 directions. Consequently, they reinforce the restoration in 2 directions with strengthening efficiency up to $50 \%$, whereas multidirectional random fibers will render a reinforcement efficiency of $38 \%$ in 1 plane and $20 \%$ in 3 dimensions ${ }^{(43)}$.

Additionally, there is a direct correlation between the fractures level and the reinforcement effect of the used material to the tooth, in this study, the levels of fractures were also assessed. Fractures at the enamel and dentin levels were considered favorable as they can be easily repaired and managed $(8,44,45)$, but when the fracture level at or below the CEJ, it requires more complicated restorative procedures or it might ended up with loss of the tooth. With the nanohybrid and bulkfill composite groups, the fracture levels were in the enamel and a few were in the dentin, suggesting good reinforcement for the weakened teeth. Using the fiber reinforced composite increased the reinforcement efficiency as the fracture levels were mostly in the enamel. The attribution might be their ability to arrest cracks propagation in the cervical direction, in addition to being able to redistribute the 3-dimensional stress without causing debonding or fracture in the cavity or restoration itself ${ }^{(46)}$.

Finally, the null hypothesis was rejected, as the fiber reinforced composite restorations did affect the fracture strength and the highest fracture strength values were obtained with SFC group. Further investigations are required to assess the influence of the same materials on different cavity designs with cusp reduction.

\section{CONCLUSION:}

Under the conditions of this study, the conclusion was that using the short fiber reinforced composite as restoration of weakened premolars reinforced the treated teeth significantly with improved fracture mode.

\section{REFERENCES:}

1. Bonilla E, Mardirossian G, and Caputo A. Fracture toughness of posterior resin composites. Quintessence International. 2001; 32: 206-210.

2. Dalpino PH, Francischone CE, Ishikiriama A, Franco EB. Fracture resistance of teeth directly and indirectly restored with composite resin and indirectly restored with ceramic materials. Am J Dent. 2002 Dec;15(6):389-94.

3. Massa F, Dias C, Blos CE. Resistance to fracture of mandibular premolars restored using post-and-core systems. Quintessence Int. 2010 Jan;41(1):49-57.

4. Bichacho N. The centripetal build-up for composite resin posterior restorations. Practical Periodontics and Aesthetic Dentistry.1994; 6: 17-24.

5. Bhardwaj T, Solmon P, and Parameswaran A. Tooth restored with composite resin-a comparative analysis. Trends in Biomaterials \& Artificial Organs. 2002; 15: 57-60.

6. Eakle W. Fracture resistance of teeth restored with class II bonded composite resin. Journal of Dental Research.1986; 65: 149-153. 
7. Solomon P, Krishna G, Parammeswaran A, Pradeep G, and Kandaswamy D. Fracture resistance of premolar teeth with class II preparations restored with light cured composite with beta quartz inserts, light cured composite and silver amalgam in comparison with intact unrestored teeth-An in vitro study. Journal of Conservative dentistry. 2007;10:122-128.

8. Sengun A, Cobankara FK, Orucoglu H. Effect of a new restoration technique on fracture resistance of endodontically treated teeth. Dent Traumatol. 2008;24:214-9.

9. Garoushi, S., Vallittu, P. K. and Lassila, L. V. J. Use of short fiber-reinforced composite with semi-interpenetrating polymer network matrix in fixed partial dentures. Journal of dentistry. (2007c); 35(5): 403-8.

10. Garoushi S, Vallittu PK, Lassila LVJ. Short glass fiber reinforced restorative composite resin with semiinterpenetrating polymer network matrix. Dent Mater. 2007;23: 1356-62.

11. Garoushi S, Vallittu PK, Lassila LVJ. Fracture toughness, compressive strength and load-bearing capacity of short glass fiber reinforced composite resin. Chin J Dent Res. 2011;14:15-9.

12. Garoushi S, Hatem M, Lassila LVJ, et al. The effect of short fiber composite base on micro leakage and loadbearing capacity of posterior restorations. Acta Biomater Odontol Scand. 2015;1:6-12.

13. Ilie $\mathrm{N}$, and Hickel R. Investigations on a methacrylate based flowable composite based on the SDR ${ }^{\mathrm{TM}}$ technology. Dental Material.2011;27:348-55.

14. Luthira A, Srirekha A, Hegde J, et al. The reinforcement of polyethylene fiber and composite impregnated glass fiber on fracture resistance of endodontically treated teeth: An in vitro study. J Conserv Dent. 2012;15:372-6.

15. Abouelleil, H., Pradelle, N., Villat, C., Colon, P. and Grosgogeat, B. Comparison of mechanical properties of a new fiber reinforced composite and bulk filling composites. Rest dent and endo. 2015; 40(4): 262-70.

16. Petersen RC. Discontinuous fiber-reinforced composites above critical length. J Dent Res 2005;84:365-70.

17. Schreiber CK. Polymethylmethacrylate reinforced with carbon fibres. Br Dent J. 1971;130:29-30.

18. Sengun, A., Cobankara, F. K. and Orucoglu, H. Effect of a new restoration technique on fracture resistance of endodontically treated teeth. Dental Traumatology. 2008; 24(2):214-19.
19. Zhang, M. and Matinlinna, J. P. E-Glass Fiber Reinforced Composites in Dental Applications. Silicon. 2012; 4(1): $73-8$.

20. Siso, S. H., Hürmüzlü, F., Turgut, M., Altundaşar, E., Serper, A. and Er, K. Fracture resistance of the buccal cusps of root filled maxillary premolar teeth restored with various techniques. Int endo j. 2007; 40(3):161-168.

21. Ahmad M Al-Thobity, Abdulmalik Altaher, Abdullah Alharbi, Mutasim Elnour. An in vitro comparison of the fracture resistance of standard and modified mesio-occluso-distal cavity designs restored with resin composite restoration. Int J of Health Sci.2018; 12(2): 24-8.

22. Kikuti W, Chaves F, Hipolito V, Rorigues F, and Alpino $P$. Fracture resistance of teeth restored with different resin based restorative systems. Braz O Res. 2012;26:275-281.

23. Moorthy A, Hogg C, Dowling A, Grufferty B, Benetti A, and Fleming G. Cuspal deflection and microleakage in premolar teeth restored with bulk fill flowable resin based composite base materials. Journal of Dentistry. 2012;40: 500-505.

24. Ana Luíza Serralha de Velloso VIANNA, Célio Jesus do PRADO, Aline Aredes BICALHO, Renata Afonso da Silva PEREIRA, Flávio Domingues das NEVES, Carlos José SOARES. Effect of cavity preparation design and ceramic type on the stress distribution, strain and fracture resistance of CAD/CAM onlays in molars. J Appl Oral Sci. 2018;26:1-10.

25. Finan, L., Palin, W. M., Moskwa, N., McGinley, E. L. and Fleming, G. J. P. The influence of irradiation potential on the degree of conversion and mechanical properties of two bulk-fill flowable RBC base materials. The Academy of Dent Mat. 2013; 29(8):906-12.

26. Goracci, C., Cadenaro, M., Fontanive, L., Giangrosso, G., Juloski, J., Vichi, A. and Ferrari, M. Polymerization efficiency and flexural strength of low-stress restorative composites. The Academy of Dent Mat. The Academy of Dent Mat. 2014; 30(6): 688-94.

27. Rosatto, C. M. P., Bicalho, A. A., Veríssimo, C., Bragança, G. F., Rodrigues, M. P., Tantbirojn, D., Versluis, A. and Soares, C. J. Mechanical properties, shrinkage stress , cuspal strain and fracture resistance of molars restored with resin composite. J of Dent. 2015; 43(12):1519-28.

28. Vahid, N. A. and Manjunath, M. K. comparison of fracture resistance of maxillary first premolars with class ii mesiooccluso-distal distal ( mod ) cavities restored with newer 
resin based composites - an ex vivo study', int j of curr res. 2016; 8(4):29814-20.

29. Fahad, F. and Majeed, M. A.-R. Fracture resistance of weakened premolars restored with sonically-activated composite , bulk-filled and incrementally-filled composites ( A comparative in vitro study )', Restorative Dentistry. 2014; 26(4): 22-27.

30. Baban, L. M. and Atiyah, A. H. fracture resistance of teeth directly and indirectly restored with composite resin. Restorative Dentistry. 2014; 26(1):7-15.

31. Toz, T., Tuncer, S., Bozkurt, F. Ö., Tuncer, A. K. and Gözükara Bağ, H. The effect of bulk-fill flowable composites on the fracture resistance and cuspal deflection of endodontically treated premolars', J of Adh Sci and Tech. 2015: 29(15):37-41.

32. Didem, A., Gözde, Y. and Nurhan, Ö. Comparative Mechanical Properties of Bulk-Fill Resins. Open Journal of Composite Materials. 2014; 4(April): 117-121.

33. Kolbeck C, Rosentritt M, Lang R, et al. In vitro study of fracture strength and marginal adaptation of polyethylene-fiber-reinforced-composite versus glass-fiber- reinforced-composite fixed partial dentures. J Oral Rehabil. 2002;29:668-74.

34. Hamza TA, Rosensteil SF, Mohammed M, et al. The effect of fiber reinforcement on the Fracture toughness and flexural strength of provisional restorative resins. J Prosthet Dent. 2004;91:258-64.

35. Vallittu PK. The effect of void space and polymerisation time on transverse strength of acrylic-glass fiber composite. J Oral Rehabil 1995;22:257-61.

36. Tamse A, Zilburg I, Halpern J. Vertical root fracture in adjacent maxillary premolars: an endodontic-prosthetic perplexity. Int Endod J 1998;31:127-32.

37. Garoushi S, Lassila LV, Tezvergil A, et al. Load bearing capacity of fibre-reinforced and particulate filler composite resin combination. J Dent 2006;34:179-84.

38. Dyer SR, Lassilla LV, Jokinen M, et al. Effect of fiber positioning and orienta- tion on fracture load of fiber reinforced materials. Dent Mater 2004;20: 947-50.

39. Garoushi S, S€ailynojac E, Vallittu PK, et al. Physical properties and depth of cure of a new short fiber reinforced composite. Dent Mater 2013;29:835-41.

40. Belli S, Erdemir A, Yildirim C. Reinforcement effect of polyethylene fiber in root filled teeth: comparison of two restoration techniques. Int Endod J 2006;39: 136-42.

41. Attavar SH, Nadig PL. An in vitro evaluation of the fracture resistance of endodon- tically treated single rooted premolar fractured vertically and reattached using two different fiber reinforced composites. Indian J Appl Res $2015 ; 5: 472-4$.

42. Oskee PA, Ajami AA, Navamipour EJ, et al. The effect of three composite fiber inser- tion techniques in root filled teeth. J Endod 2009;35:413-6.

43. Krenchel H. Fiber Reinforcement Theoretical and Practical Investigations of the Elasticity and Strength of Fiber Reinforced Materials. Copenhagen: Academisk Forlag; 1964.

44. Ramy Ahmed Wafaie, Ashraf Ibrahim Ali and Salah Hasab Mahmoud. Fracture resistance of prepared premolars restored with bonded new lab composite and all-ceramic inlay/onlay restorations: Laboratory study. J Esthet Restor Dent. 2018;30:229-39.

45. VA Mergulha o LS de Mendonc, a MS de Albuquerque R Braz Fracture Resistance of Endodontically Treated Maxillary Premolars Restored With Different Methods. Op Dent. 2019; 44-1: E1-E11 .

46. Karbhari VM, Wang Q. Influence of triaxial braid denier on ribbon-based fiber re-inforced dental composites. Dent Mater 2007;23:969-76. 